"This is the peer reviewed version of the following article: [Medical Education, 2013, 47, (3), pp. 227-229] which has been published in final form at [https://onlinelibrary.wiley.com/doi/abs/10.1111/medu.12116] purposes in accordance with Wiley Terms and Conditions for Self-Archiving." 
Accepted version of:

Molloy, E. and Boud, D. (2013). Seeking a different angle on feedback: learner as seeker, judge and user of performance information. (commentary) Medical Education, 47, 3, 227-229. doi:

$10.1111 /$ medu. 12116

\title{
Seeking a different angle on feedback in clinical education: the learner as seeker, judge and user of performance information
}

\author{
Elizabeth Molloy ${ }^{1} \&$ David Boud $^{2}$ \\ ${ }^{1}$ Melbourne, Victoria, Australia \\ ${ }^{2}$ Sydney, New South Wales, Australia
}

In this issue of Medical Education, Bok et al. ${ }^{1}$ report a qualitative study designed to better elucidate why and how veterinary medicine students seek feedback on their performance in the workplace. They investigated factors that might influence learners' readiness to become active players in the feedback process. The research question is welcome and timely in the discourse on feedback, in which the bulk of practice guidelines and professional development initiatives are focused on how teachers and supervisors can better deliver high-quality feedback to learners. In this commentary, we draw on our own recent work in reconceptualising feedback, ${ }^{2,3}$ which positions learners as active in seeking, generating and using feedback to change their task performance.

Many published studies demonstrate the potency of feedback as a mechanism to improve learning and performance. ${ }^{4,5}$ However, despite consensus that feedback is important for learning, the feedback literature is marked by increasing numbers of reports of dissatisfaction. ${ }^{6}$ Learners report that they do not receive feedback that is helpful for their learning; educators report the burden of giving feedback.

The fact that so much has been written about feedback without fixing the problem suggests that we might be barking up the wrong tree; that is, we need to find new ways of thinking. For this reason, Bok et al. ${ }^{1}$ are to be applauded for their research aim and study design. Rather than focusing on educators' actions, the researchers examined learners' motivations, orientation and skills in seeking and using feedback. ${ }^{1}$

A key thesis stemming from the findings of Bok et al. ${ }^{1}$ is that the effectiveness of a feedback episode is contingent on the engagement and 'seeking behaviour' of the learner. The researchers 1 lean on the explanatory frameworks offered by Ashford and Cummings ${ }^{7}$ in organisational psychology, who define feedback seeking as the process involved in the learner's inviting of feedback from external sources. Bok et al. ${ }^{1}$ found that learners' tendencies to seek or not to seek performance information from others depended on their motivations (performance versus learning), which were often tied to issues of preserving image or face. Before we further problematise influences on feedback-seeking behaviours, it is important to establish the rationale for wanting to enlist learners as active players in the feedback process. 
Positioning the learner as the seeker and user of feedback challenges the normal assumption in current feedback practice: that feedback constitutes a one-way transmission of information from a knowledgeable person to a less knowledgeable person. In other words, Bok et al., ${ }^{1}$ like other writers on feedback with constructivist sentiments, ${ }^{8-10}$ suggest that feedback is not telling. Our own definition of feedback avoids this by focusing on what learners do: '...feedback is a process whereby learners obtain information about their work in order to appreciate the similarities and differences between the appropriate standards for any given work, and the qualities of the work itself, in order to generate improved work. ${ }^{11}$ In this view, feedback in education, like feedback in nature, must lead to change. Learners who invest in their own learning needs and seek information about aspects of their practice that may need improvement are more likely to reap benefit and change their behaviours. The rewards of engaging in feedback to be derived by the learner are two-fold: firstly, learners can improve their subsequent task performance, and, secondly, learners can improve their own capacity for making judgements about their work. Helping students to develop this capacity for evaluation is key to generating successful learners and, most importantly, a workforce committed to ongoing learning.

Bok et al. ${ }^{1}$ report three key factors that influence learners' feedback seeking behaviours. The first concerns the intentions and characteristics of the feedback provider. Indeed, a substantial body of literature supports the importance of the perceived status of the 'provider', which includes his or her expertise, whether he or she is judged worthy of comment on performance, and his or her perceived intentions. ${ }^{12}$ Learners are more receptive to judgement from people whom they trust and who seem to have their best interests at heart. The second and related factor impacting the 'seeking tendency' pertains to the relationship between the feedback seeker and provider. As Bok et al. ${ }^{1}$ outline, this is not about 'getting along' or a 'personality fit'. It is about creating conditions that enable productive behaviours in learning. It is important to highlight, however, that time and continuity of contact have great impact on relationship forming. For example, a hospital placement that lasts 3 weeks and a $\mathrm{PhD}$ supervisory relationship that spans 3 years will hold very different capacities for productive feedback (and for both parties to witness and experience the outcomes of the feedback). The third factor concerns the motives of the learner. Strategic learners who are highly assessmentoriented may think they have good reason to hide their performance deficits from supervisors and may choose to avoid feedback opportunities if they suspect their performance is below par. Learners who have fragile self-efficacy may be defensive and less open to feedback opportunities. ${ }^{13}$ These learners have been described as activating their "psychological immune systems' in order to preserve a positive self-efficacy. ${ }^{14}$ Eva et al..${ }^{14}$ described two common learner responses when this immune system is activated: the learner avoids feedback opportunities, and the learner deflects external information when it is made available, holding tightly to his or her own interpretation of events. The psychological immune system is successful in preserving face, but not in encouraging learning.

Some may argue that it takes a mature learner to alert attention to aspects of his or her own practice that are less than desirable or lack mastery; to an extent, this is true. Honest selfanalysis and the seeking of others' viewpoints on characteristics of work that require improvement make the learner vulnerable if he or she is operating in an environment bound by summative assessment. If a mark is attached to longitudinal performance over a placement or clerkship, then students may feel that it serves them to hide their deficits and put their best foot forward for 'measurement'. This calls into question whether many learning opportunities should be subject to summative judgement. 
Like that of Bok et al., ${ }^{1}$ our own research leads us to think that learners, rather than 'waiting for' feedback from others, should drive the process themselves. The capacity to seek performance information from a number of sources, weigh it up against self-analysis of performance and use the resultant strategies for subsequent task improvement is not necessarily an easy undertaking. It requires orientation to the purpose of feedback, regular practice in low- and high stakes settings, and modelling from staff that includes the demonstration of seeking behaviours, and of vulnerability in discussing one's own expertise and performance improvement over time. This is the area upon which we should focus our research: how do we design curricula to generate conditions that dispose learners to seek and use feedback?

\section{References}

${ }^{1}$ Bok HGJ, Teunissen PW, Spruijt A, Fokkema JPI, van Beukelen P, Jaarsma DADC, van der Vleuten CPM. Clarifying students' feedback seeking behaviour in clinical clerkships. Med Educ 2013; 47:282-91.

${ }^{2}$ Boud D, Molloy E. Rethinking models of feedback: the challenge of design. Assess Eval Higher Educ 2012; E:1-15.

${ }^{3}$ Molloy E, Boud D. Changing conceptions of feedback. In: Boud D, Molloy E. Feedback in Higher and Professional Education. London: Routledge 2013; 11-33.

${ }^{4}$ Hattie J, Timperley H. The power of feedback. Rev Educ Res 2007; 77:81-112.

${ }^{5}$ Kluger A, DeNisi A. The effects of feedback interventions on performance: a historical review, a meta-analysis, and a preliminary feedback intervention theory. Psychol Bull 1996; 119 (2):254-84.

${ }^{6}$ Adcroft A. The mythology of feedback. High Educ Res Dev 2011; 30(4):405-19.

${ }^{7}$ Ashford S, Cummings L. Feedback as an individual resource: personal strategies of creating information. Organ Behav Hum Perform 1983; 32(3):370-98.

${ }^{8}$ Butler D, Winne P. Feedback and self-regulated learning: a theoretical synthesis. Rev Educ Res 1995; 65(3):245-81.

${ }^{9}$ Carless D, Salter D, Yang M, Lam J. Developing sustainable feedback practices. Stud Higher Educ 2011; 36(5):395-407.

${ }^{10}$ Nicol D, Macfarlane-Dick D. Formative assessment and self-regulated learning: a model and seven principles of good feedback practice. Stud High Educ 2006; 31(2):199-218.

${ }^{11}$ Boud D, Molloy E. What is the problem with feedback? In: Boud D, Molloy E. Feedback in Higher and Professional Education. London: Routledge 2013: 1-10.

${ }^{12}$ Carless D. Trust, distrust and their impact on assessment reform. Assess Eval High Educ 2009; 34 (1):79-89.

${ }^{13}$ Ilgen D, Davis A. Bearing bad news: reactions to negative performance feedback. Appl Psychol Int Rev 2000; 49:550-65.

${ }^{14}$ Eva K, Armson H, Holmboe E, Lockyer J, Loney E, Mann K, Sargeant J. Factors influencing responsiveness to feedback: on the interplay between fear, confidence, and reasoning processes. Adv Health Sci Educ 2012; 17:15-26. 